\author{
بررسى وضعيت تجارت داخلى و بينالمللى آب مجازى در ايران \\ غالامحسين كيانى \\ (تاريخ دريافت:
}

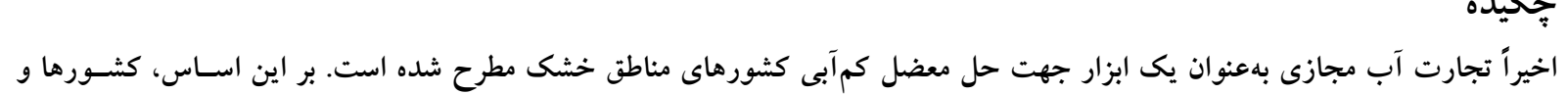

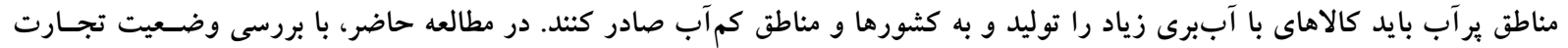

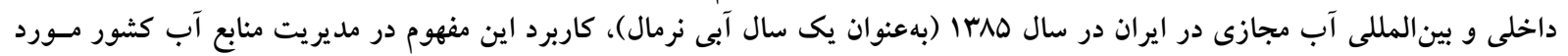

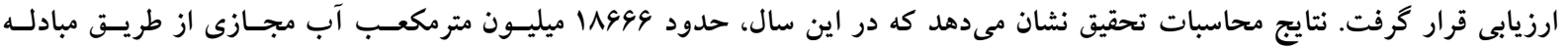

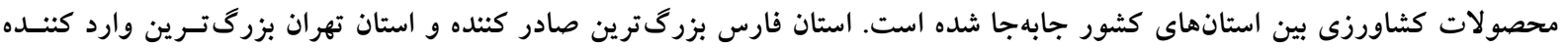

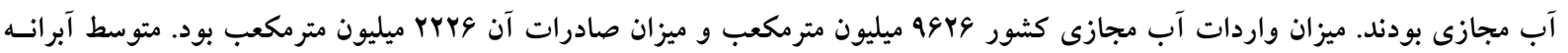

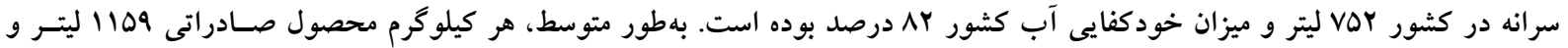

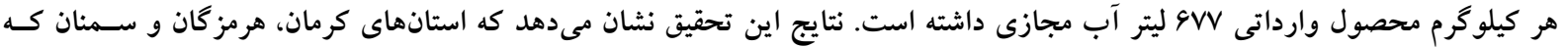

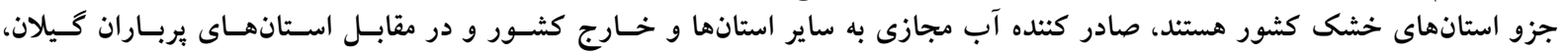

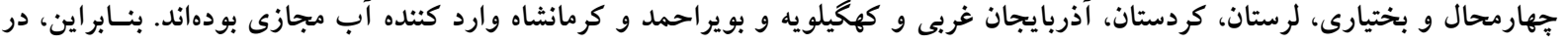

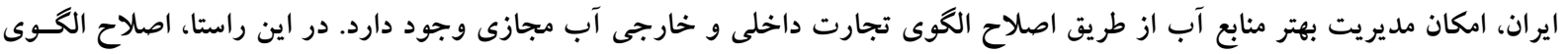

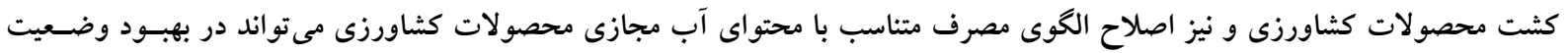
منابع آب كشور در بلندمدت مفيد واقع شوده.

وازههاى كليدى: آب مجازى، آبرانه، خودكفايى آب 
كشت در منطقه مرودشت، علاوه بر هدف حداكثرسـازى منـافع

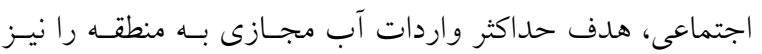

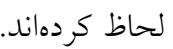

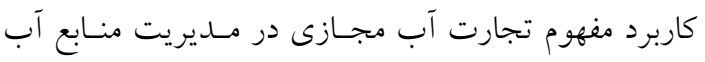

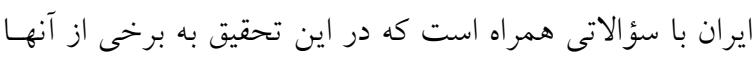

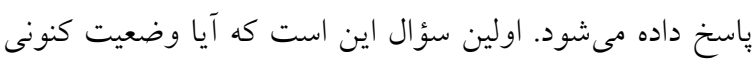

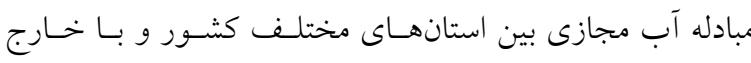

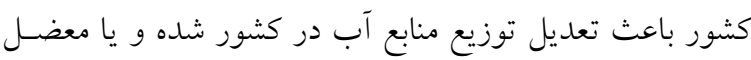

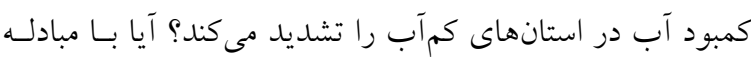

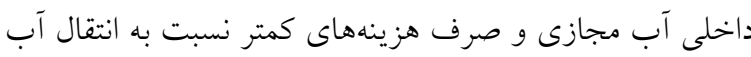

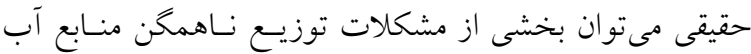

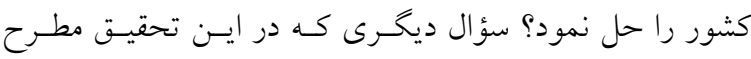

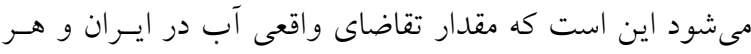

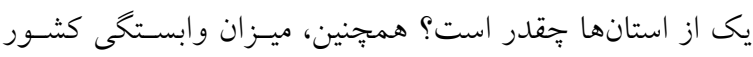

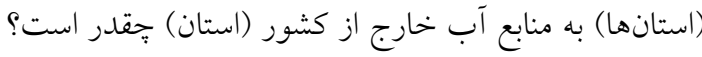

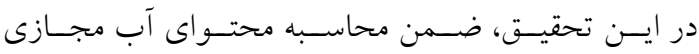

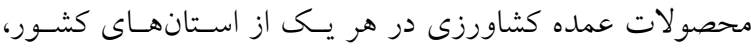
واردات و صادرات آب مجازى استانها و كشور محاسبه شده و

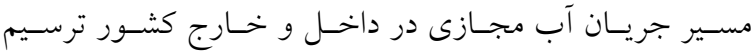

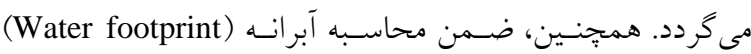

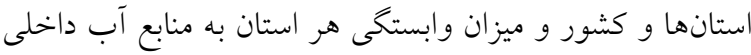

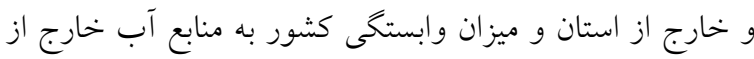

$$
\text { كشور تعيين مى مود. }
$$

\section{مواد و روشها}

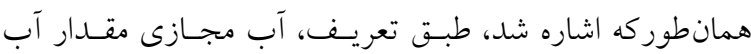
مصرف شده براى توليد مقدار معينى از محصـول مسىباشـد. در

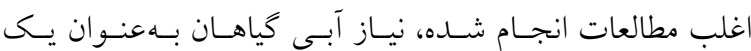
شاخص از مقــار آب مصـرف شـــه بـــاى توليـد محصـولات

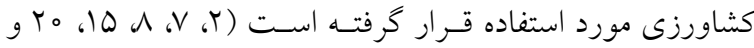

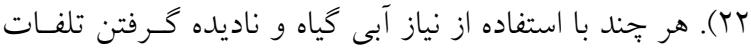

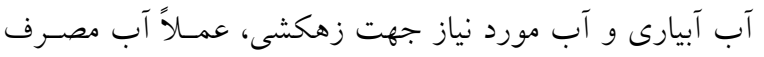

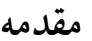

در دهلهـاى اخيـر بـهدليـل افـزايش جمعيـت و فعاليـتهـاى اقتصادى، تقاضا براى منابع آب در بخشهاى كشاورزى، شـرب آنسائ و صنعت افزايش يافته است. از سوى ديخر، بهدليل اينكه ايـران

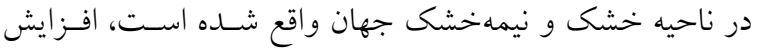

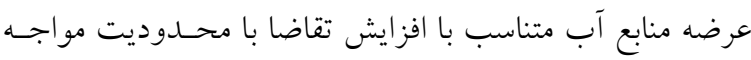

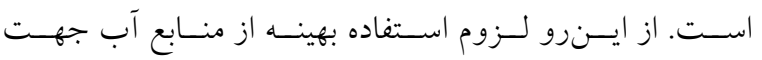

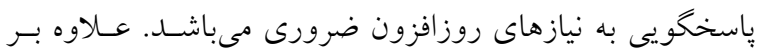

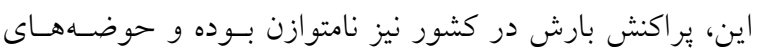

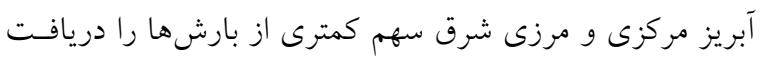

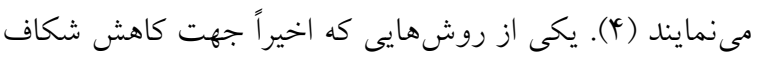

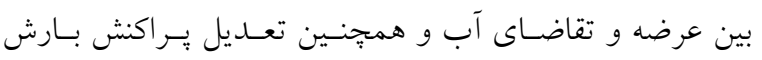

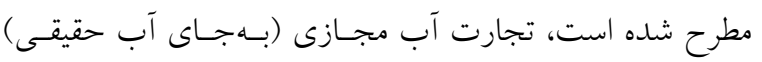

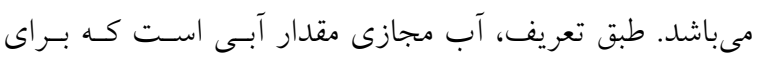

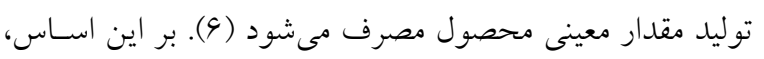

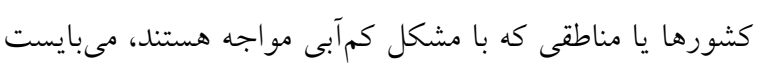

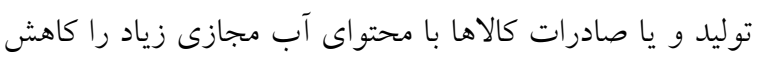

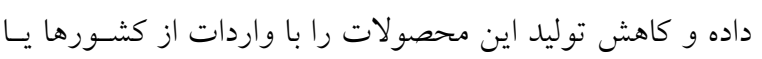

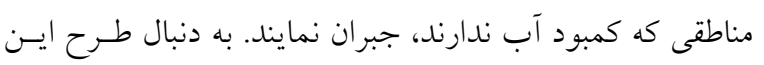

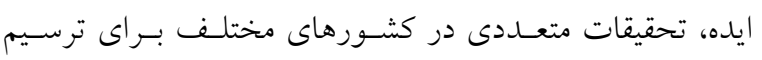

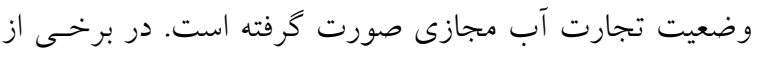

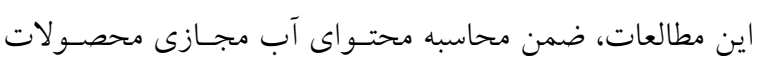

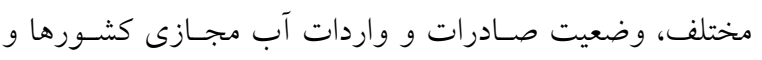

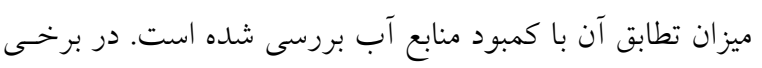

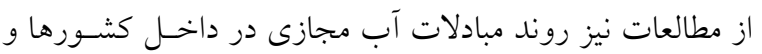

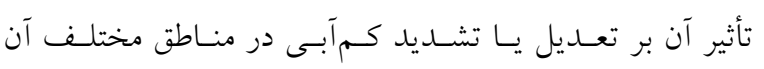

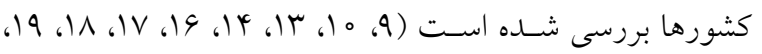
(T)

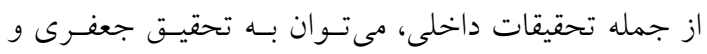

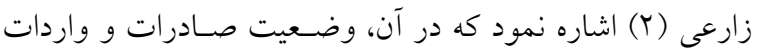

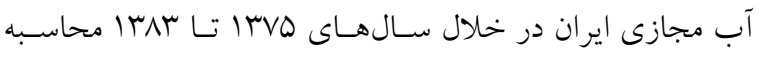
شده است. دهقانيور و بخشوده (r) نيز در تعيين الخـوى بهينـه 
شده به ساير كشورها (ناشى از صادرات كالا) مىباشد (r)): IWFP = AWU+IWW+DWW $-\mathrm{VWE}_{\text {dom }}$

$[\mathrm{r}]$ كه در آن IWFP آبرانه داخلى، AWU مقدار آب مصرف شـده

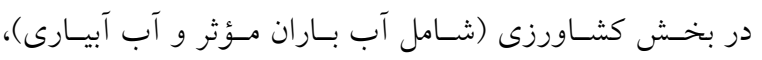

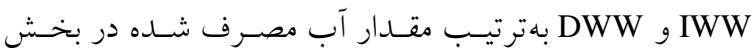

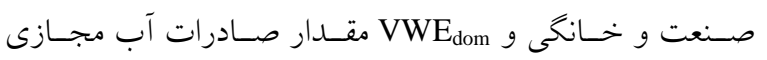
(ناشى از صادرات توليدات داخلى) مىباشند. مقدار آبرانه خارجى (EWFP) يـى كشـور حجـم مصـرف

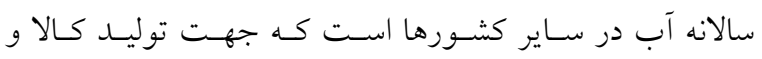
خدمات مصرفى در كشور مورد نظـر مصـرف مسى آشـود. آبرانسه

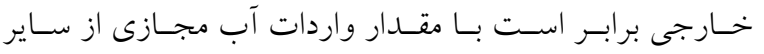
كشورها (VWI) منهاى صادرات آب مجازى به سـاير كشـورها

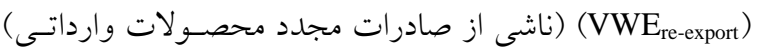

\section{EWFP $=$ VWI $-V_{W E}$ re-export}

سرانه آبرانه يك كشور يا استان يك معيار مناسب جهت مقايسه

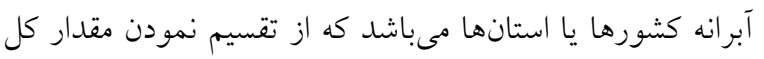

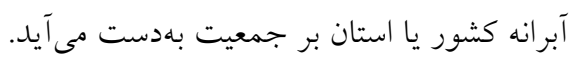
ضريب خودكفايى آب هر استان يا كشور (WSS) با استفاده از رابطه زير محاسبه مىشود:

$\mathrm{WSS}=(\mathrm{IWFP} / \mathrm{WFP})^{*} 10$

هر جقعدر مقدار اين ضريب نزديك به صفر باشـــ نشـاندهنــه

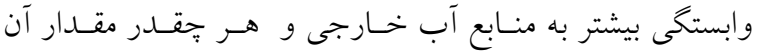

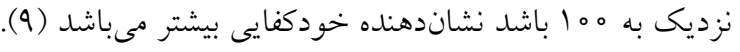
در اين تحقيق، با استفاده از تعاريف و روابـط فـوق، آبرانـهـ

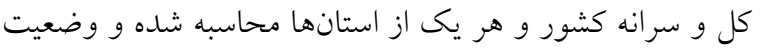

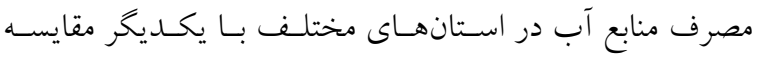

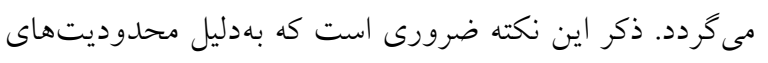

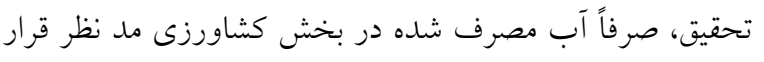

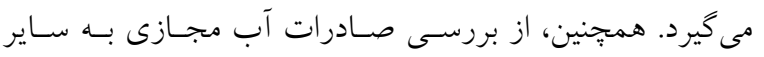

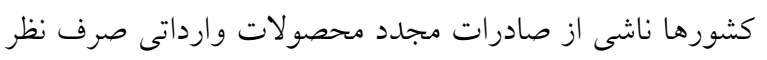
مىشود.
شده كمتر از مقدار واقعى تخمين زده مىشود (^)، امــا بـهدليـل

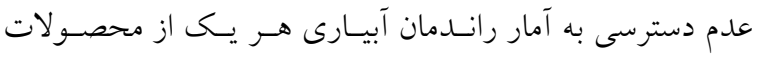
مورد مطالعه در تمام استانهاى كشور، در اين تحقيـق نيـز نيـاز

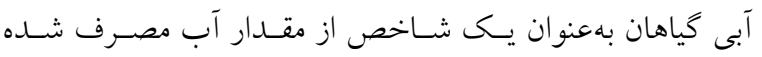

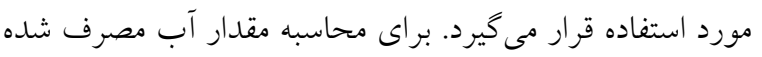

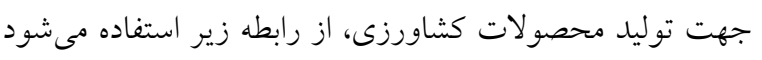

$\operatorname{SWD}(\mathrm{n}, \mathrm{c})=\frac{\mathrm{CWP}(\mathrm{n}, \mathrm{c})}{\mathrm{CY}(\mathrm{n}, \mathrm{c})}$

كه در آن SWD مقدار آب مصرف شده (مترمكعب بر تن) جهت

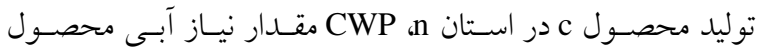
(مترمعـب در هكتـار) و CY عملكـرد توليـد (تـن بـر هكتـار)

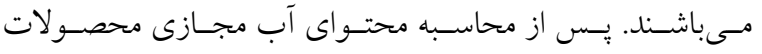

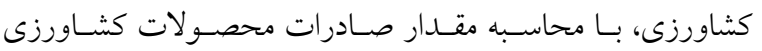

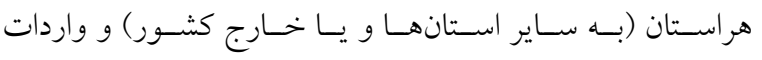

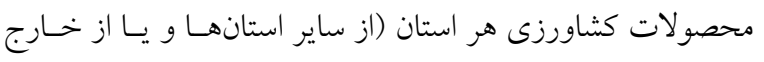

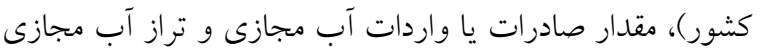

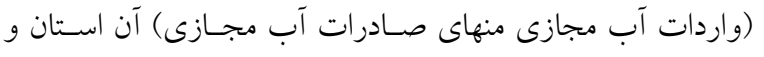

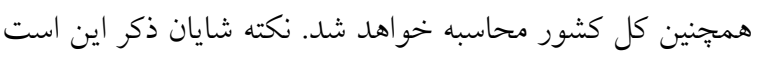

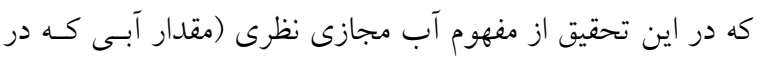

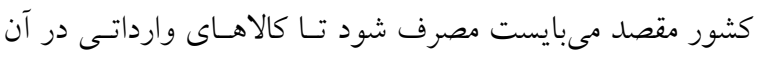

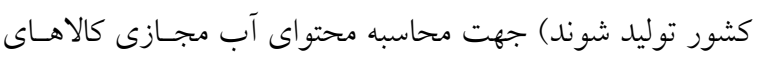
وارداتى به كشور استفاده شده است.

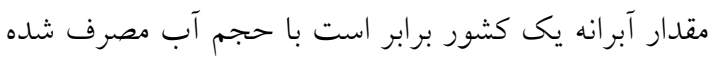

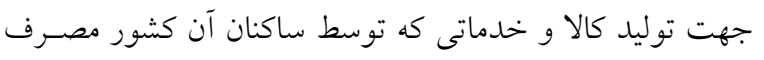

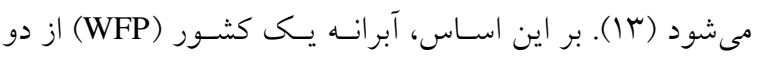

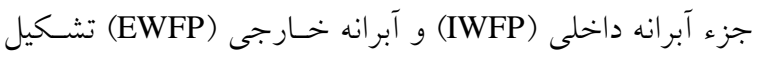

WFP $=$ IWFP + EWFP

آبرانه داخلى مقدار آب مصرف شده از منابع داخلى هـر كشـور جهت توليد كالا و خدمات مصرف شده توسط سـاكنان همـان

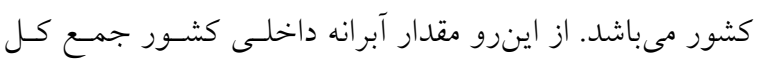
آب مصرف شده از منابع داخلى منهاى حجم آب مجازى صادر 
كشور نيز به نسبت توسط استانهايى كه با مازاد عرضـه مواجـه

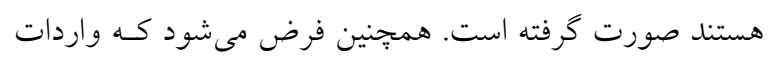

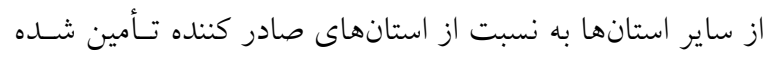

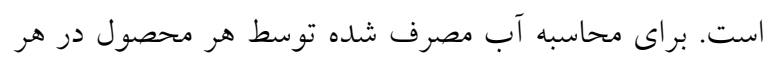

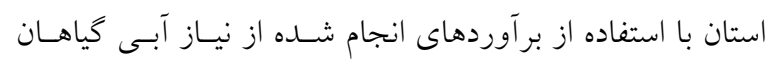

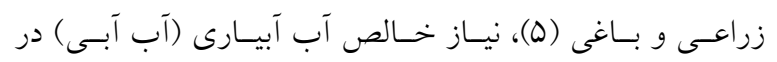

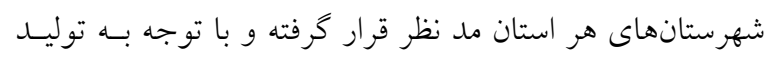
هر شهرستان متوسط وزنى براى استان محاسبه كرديد.

\section{نتايج و بحث}

در سال هیr| استان تهران با واردات خوزستان با صادرات هـ/\% ميليون تن محصولات عمده زراعى لهى و باغى، بزرگترين تراز تجارى منفى و مثبت را با ساير استانها و خارج كشور داشتهاند. در اين سال، ميزان واردات و و صادرات

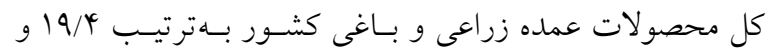

$$
\text { / اميليون تن بوده است. }
$$

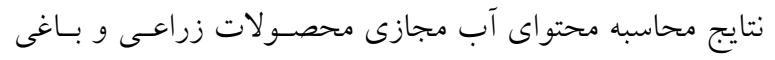

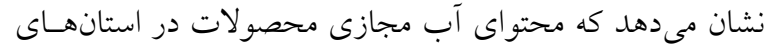

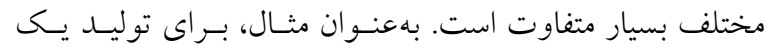

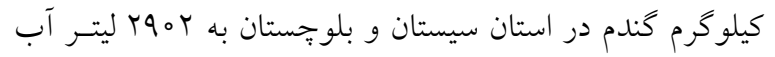

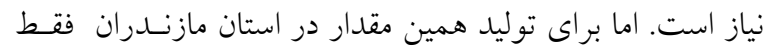
به هاه ليتر آب نياز مىباشد. اختلاف در محتـواى آب مجـازى لمعين

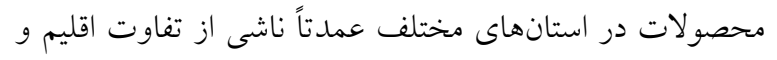

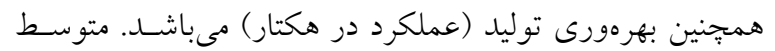
آب مجازى محصولات زراعى و باغى كشور در شكلهـاى (1)

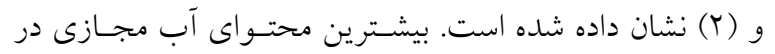

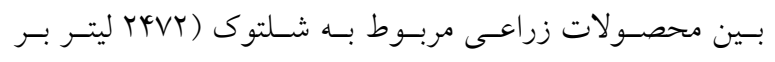

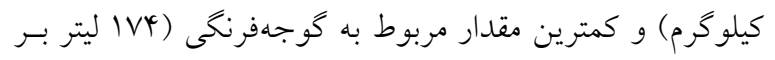

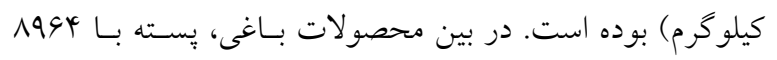

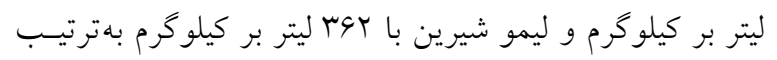
بيشترين و كمترين محتواى آب مجازى را داشتهاند.

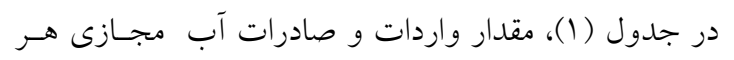

آمار و اطلاعات مورد استفاده

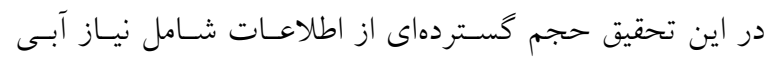
محصولات، مقدار توليد و مصـرف \& 1 محصـول زراعى و 10

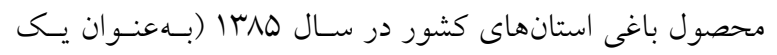

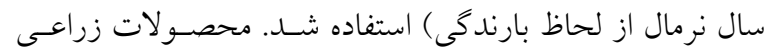

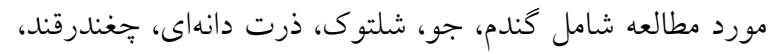

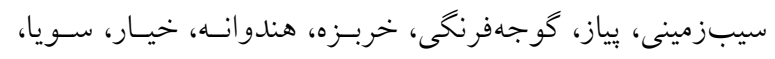

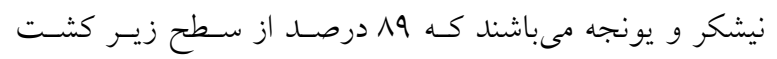

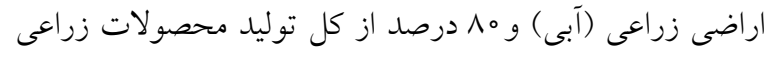

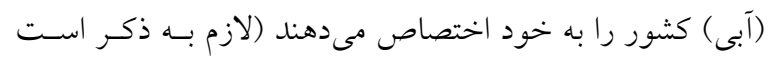

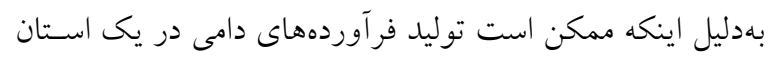

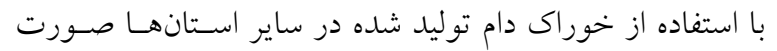

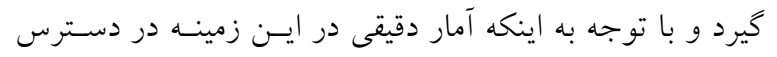

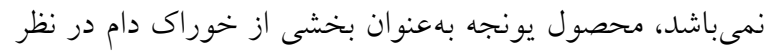

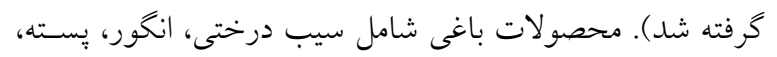

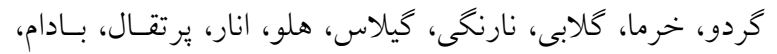

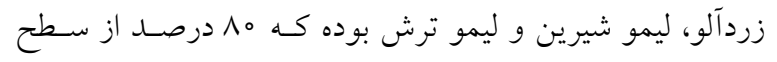
باغها و و9 درصد از محصولات بـاغى توليسـ شــده را تشـكيل

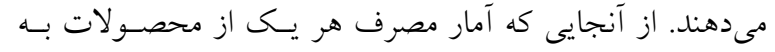

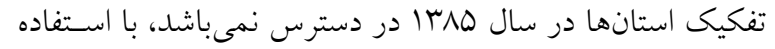

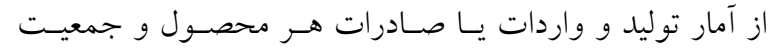

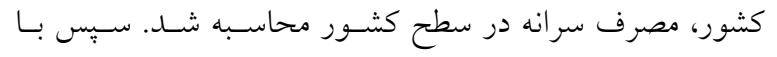
فرض مشابه بودن مصرف سرانه در همه استانها و با توجـهـ بــهـ

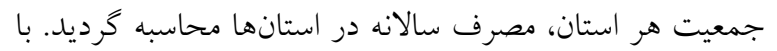
محاسبه تفاضل توليد و مصرف، مقدار صادرات يـا واردات هـر

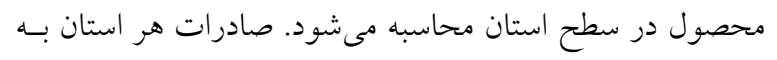

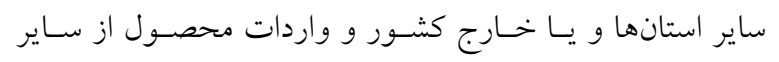

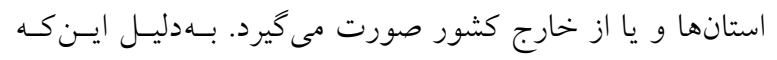
نمى توان مشخص كرد كه محصولات وارد شده از خارج كشور

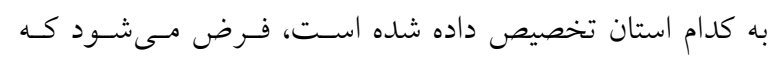

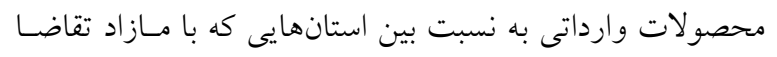
مواجه بودهاند، ارسال شده است. صادرات محصـول بـه خـارج 

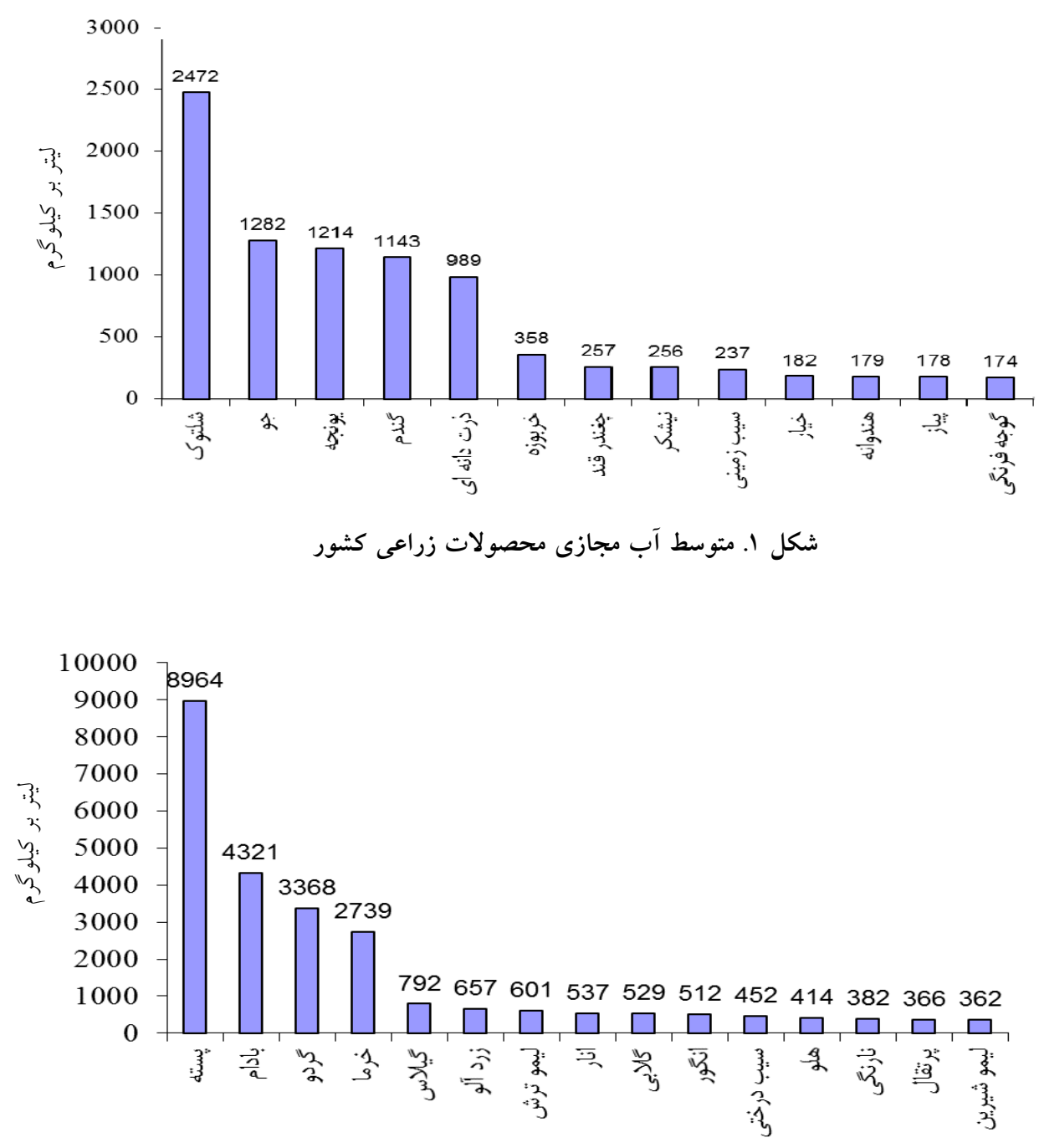

شكل r. محتواى آب مجازى محصولات عمده باغى كشور

در سال هم/1، كشور ايران با واردات 9/9 ميليارد مترمكعب

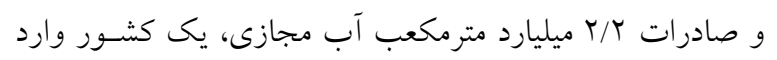

كننده خالص مجازى بـوده اسـت. در ايسـن سـال، مقــدار آبرانـه

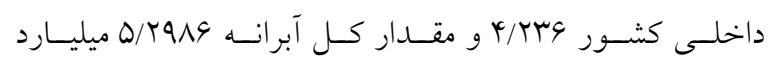

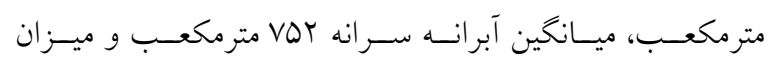

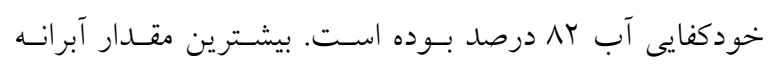

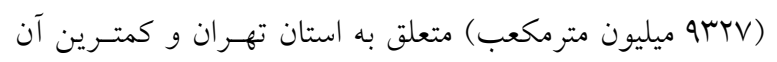

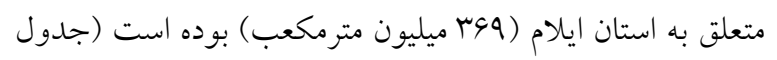

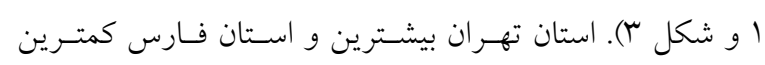

استان ناشى از افـزايش واردات و صـادرات محصـولات عمــده

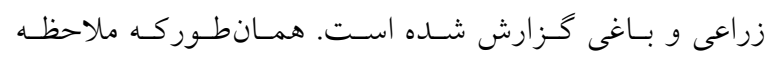

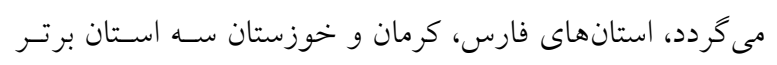

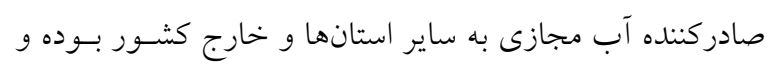

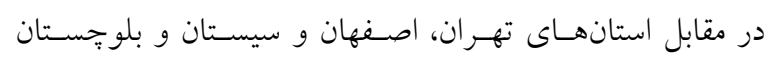

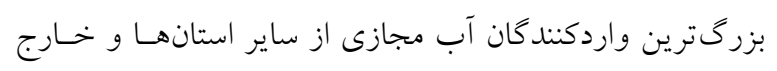
كشور بودهاند. نكته قابل توجه اين است كه عليرغم اينكه استان

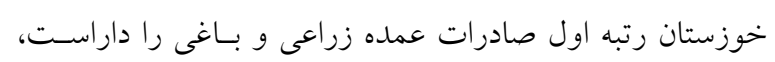
اما از لحاظ صادرات آب مجازى در رتبه سوم قرار دارد. 


\begin{tabular}{|c|c|c|c|c|c|c|c|c|c|c|c|c|}
\hline \multicolumn{13}{|c|}{ جدول ا. واردات و صادرات آب مجازى و آبرانه استانها (ميليون مترمكعب) در سال IN^ه } \\
\hline \multicolumn{5}{|c|}{ آبر انه } & \multicolumn{7}{|c|}{ آب مجازى } & \multirow[b]{3}{*}{ استان } \\
\hline \multirow[b]{2}{*}{ 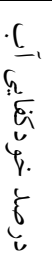 } & \multirow[b]{2}{*}{ 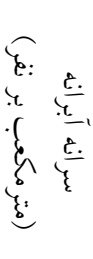 } & \multirow[b]{2}{*}{$\begin{array}{l}\frac{\varepsilon}{c} \\
c_{1} \\
\bar{c} \\
\bar{c}\end{array}$} & \multirow[b]{2}{*}{$\begin{array}{l}q \\
\dot{r} \\
\bar{r} \\
\underline{\varepsilon} \\
\underline{\varepsilon}\end{array}$} & \multirow[b]{2}{*}{$\begin{array}{l}\frac{G}{\bar{r}} \\
\frac{\varepsilon}{v} \\
\frac{\varepsilon}{\varepsilon_{-}}\end{array}$} & \multirow[b]{2}{*}{ 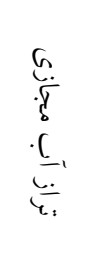 } & \multicolumn{3}{|c|}{ صادرات } & \multicolumn{3}{|c|}{ 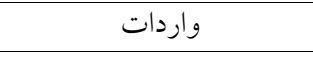 } & \\
\hline & & & & & & 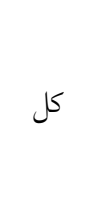 & 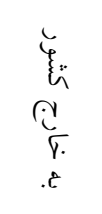 & 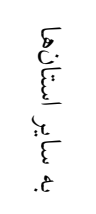 & كل & 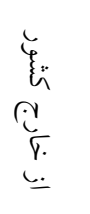 & 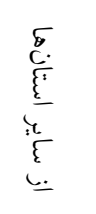 & \\
\hline$\Delta r$ & 941 & V^V & rvA & $4 \circ q$ & $-\Lambda$ & rVo & 19 & MQY & rVA & IrN & TYO & اردبيل \\
\hline$\Delta \wedge$ & $V Q \circ$ & MYlA & lyty & $19 V 4$ & $-11 \mathrm{VI}$ & $r V r$ & 19 & $T \Delta D$ & I fye & 901 & NHG & اصفهان \\
\hline Gr & GVG & ra9 & rir & 109 & -111 & 100 & 19 & $\wedge r$ & rIT & 94 & $14 V$ & ايلام \\
\hline ro & qAr & TYEY & I FVY & 911 & $-V Y_{0}$ & Vry & r。 & $V \circ Y^{f}$ & I FVY & GTr & NFT & آذربايجان شرقى \\
\hline$\uparrow \wedge$ & 994 & 1991 & $104 \mathrm{~V}$ & $9 \Delta Y$ & $-Y 19$ & $11 \wedge$ & HT & VVA & I०rV & rNo & $9 \Delta T$ & آذربايجان غربى \\
\hline ry & $N^{\mu}$ & $90^{\circ}$ & 199 & 100 & -21 & Yro & V^ & MFV & 199 & 190 & Mrg & بوشهر \\
\hline 11 & 990 & QTTV & ATVE & $100 \mu$ & $-\lambda Y I Y$ & GY & $\circ$ & GY & $A T V Y$ & rQDS & $\Delta V \backslash \Lambda$ & تهران \\
\hline 09 & Vrr & 949 & TQV & rVI & $-\varphi_{0}$ & rIV & $r$ & rir & TQV & 100 & IOT & جهارمحال و \\
\hline 01 & QYT & 900 & r91 & $r \circ q$ & - TOr & 快 & $\circ$ & ґ & rq1 & $\Lambda \Delta$ & r०9 & خراسان جنوبى \\
\hline 91 & 119 & rOVA & IVqF & TVAD & $-\wedge \vee \wedge$ & 919 & $\Lambda \mu$ & $\Delta \mu$ & IVq4 & VIV & $10 V \mathrm{~V}$ & خراسان رضوى \\
\hline$\Delta V$ & Var & apt & TVQ & ras & $-\Delta \psi$ & rYI & r & r19 & TVQ & 109 & 199 & خراسان شمالى \\
\hline$v r$ & $\wedge 91$ & rлrq & 1049 & rVal & 10Q9 & YY०D & 90 & TQ1。 & 1049 & TYG & NTH & خوزستان \\
\hline Or & var & V90 & rVo & 190 & $\Delta \wedge$ & FYA & 10 & 419 & rVo & 109 & rit & زنجان \\
\hline 94 & $\Delta Y^{r}$ & YAS & IVG & M。 & 90 & TVI & r。 & TEY & IV9 & Vq & $9 V$ & سمنان \\
\hline Yo & $\Lambda T V$ & 1919 & 1191 & V91 & -990 & YMI & ky & IAV & 1191 & pra & VQS & سلو جستان و \\
\hline$\Lambda \uparrow$ & $\Lambda r_{0}$ & ryoo & $\Delta \wedge Y$ & Mols & מצT & $r \Lambda \circ V$ & $\wedge \mathrm{V}$ & TVYI & $\Delta \wedge F$ & 194 & $r q 0$ & فارس \\
\hline GY & GKY & VTr & TVG & YQA & FTr & 999 & 19 & 9N & TVG & 111 & 190 & قزوين \\
\hline$M$ & $V T$ & VVT & QTH & 隹 & $-r q \circ$ & $1 \mathrm{kr}$ & $\circ$ & $14 \pi$ & TH & $M M$ & Mus & قم \\
\hline py & $v \notin q$ & $1 \circ \sqrt{9}$ & G०r & FV & $-Q T \Delta$ & VA & 9 & VT & 9.r & rma & ray & كردستان \\
\hline$\Delta r$ & 910 & $110 \mathrm{~V}$ & QHT & GYO & -94 & $49 \Lambda$ & $\circ$ & 491 & QHT & 109 & rVT & كرمانشاه \\
\hline Gr & VIr & For & IVt & TVA & $-V 4$ & 91 & 0 & 94 & IVt & 09 & 110 & كهيخيلويه و \\
\hline $9 V$ & 109 & TrVG & $V+1$ & lorA & $190 \mathrm{~V}$ & r991 & IMTK & IrVt & $v+1$ & אחי & $y \circ \varphi^{r}$ & كرمان \\
\hline or & VTI & 1199 & $\Delta 01$ & 910 & 94 & 940 & $r$ & GKT & $\Delta Q 1$ & IVT & rvq & كلستان \\
\hline IV & 994 & 1994 & 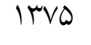 & r^q & DTY & 114 & $\circ$ & $11 \mathrm{kr}$ & $1 \% V D$ & M/ & $1 \circ \Delta V$ & كيالن \\
\hline$q \mu$ & $\Lambda V V$ & $10 \cdot 0$ & $\Delta G Y$ & 941 & מצז- & $|\mu|$ & 19 & 110 & DGY & $19 r$ & MVT & لرستان \\
\hline r & $9 \vee 0$ & $19 V \pi$ & $|O Y|$ & 401 & 111 & $I V \circ Y$ & $\circ$ & $I V \circ Y$ & $|O Y|$ & rNI & 1140 & مازندران \\
\hline Dr & 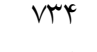 & 991 & YQV & QMY & 1。 & $\Delta{ }^{\prime} \Lambda$ & r & OrG & $Y \Delta \Lambda$ & r०q & TYA & مركزى \\
\hline rG & VAr & loft & VVI & TVT & 191 & QTr & IKY & $\Lambda \circ \wedge$ & VI & TYI & QHI & هر مز گان \\
\hline$\Delta V$ & 9NY & 1194 & 199 & 990 & TOM & VQY & ro & VTr & 1999 & rIT & TAV & همدان \\
\hline$\Delta \omega$ & MN & $\Lambda \vee Q$ & rar & YA & $-k T$ & $r \omega \circ$ & 109 & 190 & rar & 101 & Trd & يزد \\
\hline$\Lambda r$ & VQY & $0 Y 9 \wedge 9$ & 9949 & Frrgo & $-V \varphi_{0} \circ$ & $r \circ \wedge 9 T$ & TMTD & 111994 & TAYQT & 99Y4 & 111999 & كل كشور \\
\hline
\end{tabular}




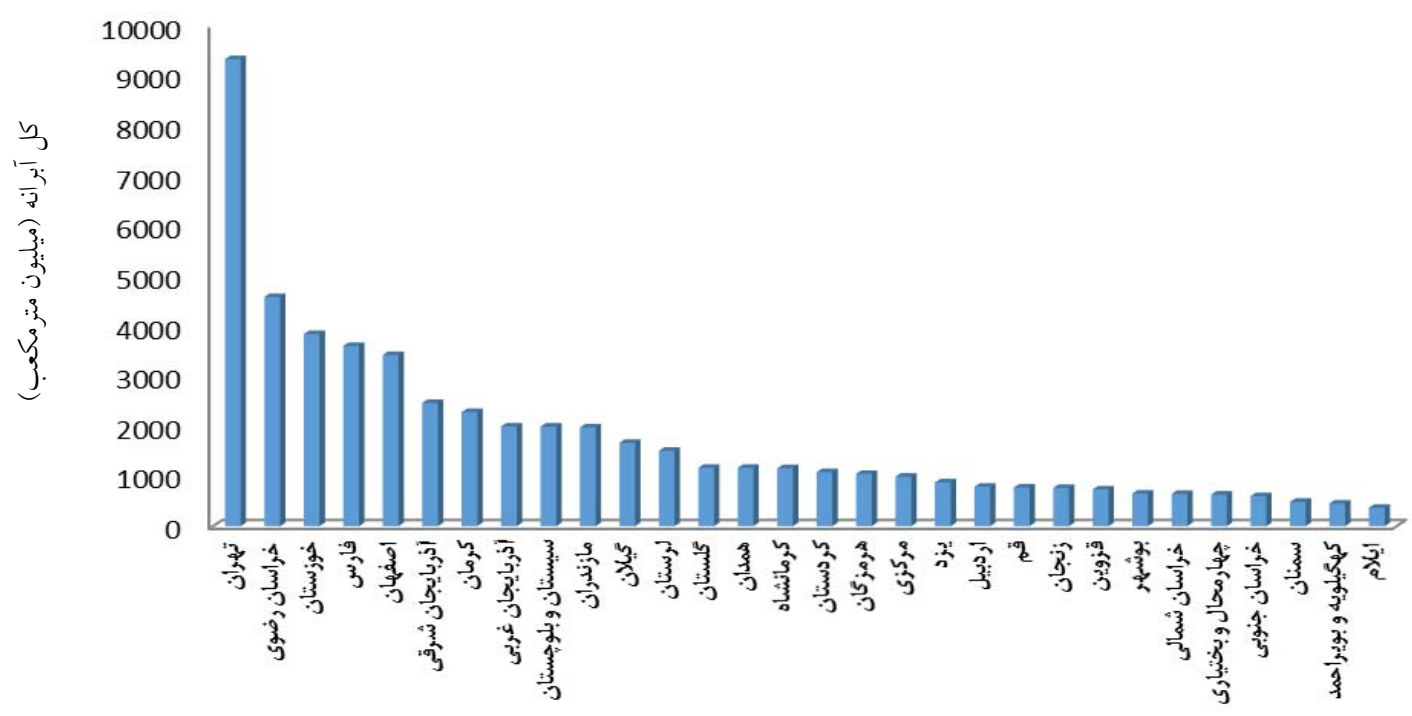

شكل r. مقدار كل آبرانه استانها (ميليون مترمكعب)

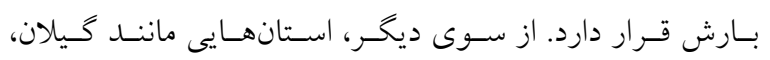

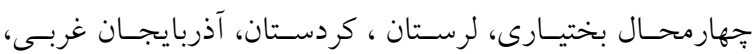

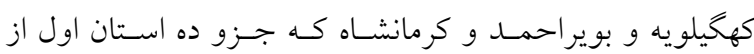

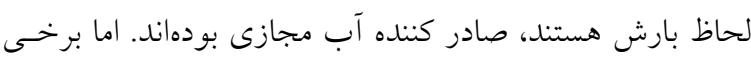

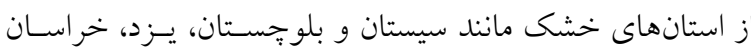
رضوى، قم، اصفهان، بوشهر و تهران كه جزو ده استان كم باران

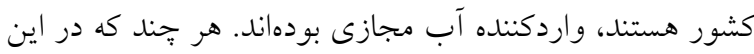

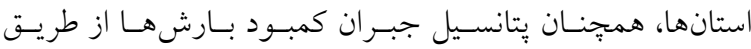

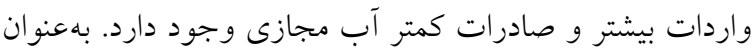
مثال، در استان يزد كه سالانه با صرف هزينههاى كزاف كمتر از

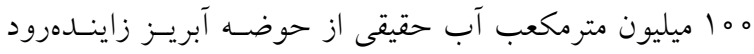

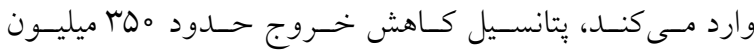
مترمكعب آب به صورت مجازى از اين استان وجود دارد.

\section{نتيجه گيرى}

طبق نظريه هيكسجر - اوهلين (11 و سا) انتظار مىرود كشور و

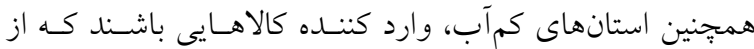
نهاده كميابتر آب (نسبت به ساير نهادهها مثل زمين يا نيسروى كار) بيشتر در توليد آنها استفاده شده و بـرعكس، صـادر كنتـده

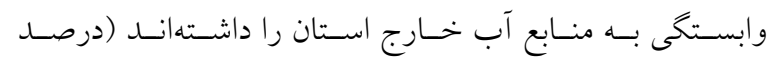

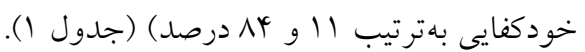

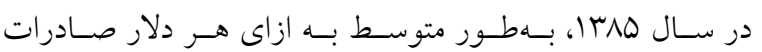
محصولات كشاورزى، ORV اليتر آب نيز صادر شده كه در ايسن

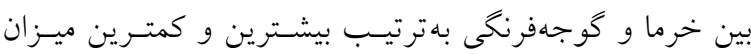

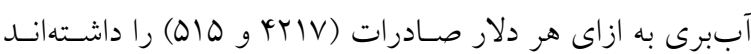

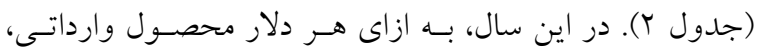

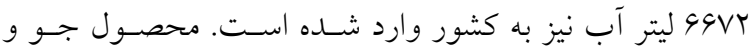

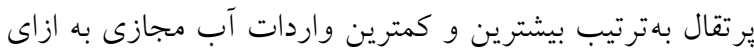

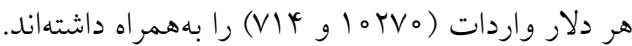

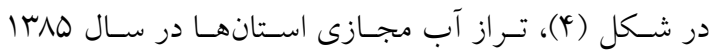
(ميليون مترمكعب) و در شكل (ه) ارتفاع بارش استانها در اين

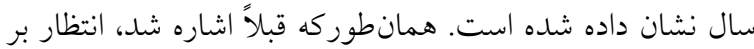

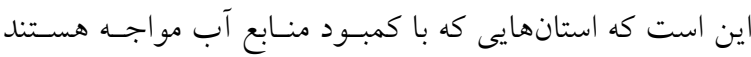

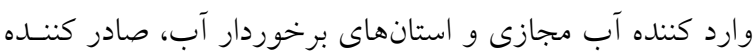
آب مجازى باشند. اما مقايسه شكلهاى (Y) و (b) نشان مىدهد كه از بين الاستان صادر كننده آب مجازى فقطط جهار استان جزو استانهاى برتر از لحاظ بارش هستند. اسـتان كرمـان، كـه

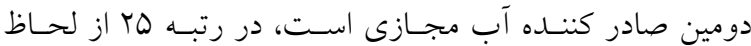


نشريه علوم آب و خاك (علوم و فنون كشاورزى و منابع طبيعى) / سال بيست و دو / شماره يك/ بهار IrqV

\begin{tabular}{|c|c|c|c|c|}
\hline \multicolumn{5}{|c|}{ جدول r. نسبت آب مجازى به ارزش صادرات و واردات، به تفكيك محصول } \\
\hline \multicolumn{5}{|c|}{ صادرات } \\
\hline به صادرات (ليتربر دلار) مجازى & 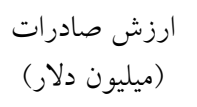 & (ميليون مترمكعب) مجازى) & صادرات (هزار تن) & محصول \\
\hline $11 \circ 4$ & 49 & $\Delta Y$ & YYI & سيبزمينى \\
\hline IVAS & 14 & ro & 1149 & يبياز \\
\hline 010 & $9 \wedge$ & ro & $r \circ Q$ & كوجه فرنكى \\
\hline 1100 & r。 & س & $r 01$ & هندوانه \\
\hline 1000 & $1 \circ \mathrm{V}$ & $1 \circ V$ & G०r & خيار \\
\hline 1.94 & $\Lambda \circ$ & $\wedge \otimes$ & TYV & سيب درختى \\
\hline IKVT & 1011 & 11499 & 19r & يسته \\
\hline FIIV & 94 & rM & Ifr & خرما \\
\hline IOTV & $140 \Lambda$ & THTS & $19 T 1$ & جمع كل \\
\hline \multicolumn{5}{|c|}{ واردات } \\
\hline واردات (ليتر بر دلار) مجازى به & $\begin{array}{l}\text { ارزش واردات } \\
\text { (ميليون دلار) }\end{array}$ & (ميليون مترمكعب) مجازى) & واردات (هزار تن) & محصول \\
\hline $9 \circ \Delta r$ & V9 & 490 & rr人 & كندم \\
\hline I.TVO & rv & r的。 & $r \circ V$ & جو \\
\hline OVVI & DQY & MYYA & 1994 & شلتوى \\
\hline VAYO & rVY & سחי & TI1。 & ذرت دانهاى \\
\hline $919 V$ & r99 & MUT & $91 \circ 4$ & جغندرقند \\
\hline 9149 & 149 & IYGY & $\Delta V Y$ & نيشكر \\
\hline VIr & 14 & 10 & س & يرتقال \\
\hline $99 \mathrm{VT}$ & IfkT & QSTA & IFTYG & جمع كل \\
\hline
\end{tabular}

مأخذ: يافتههاى تحقيق و (11)

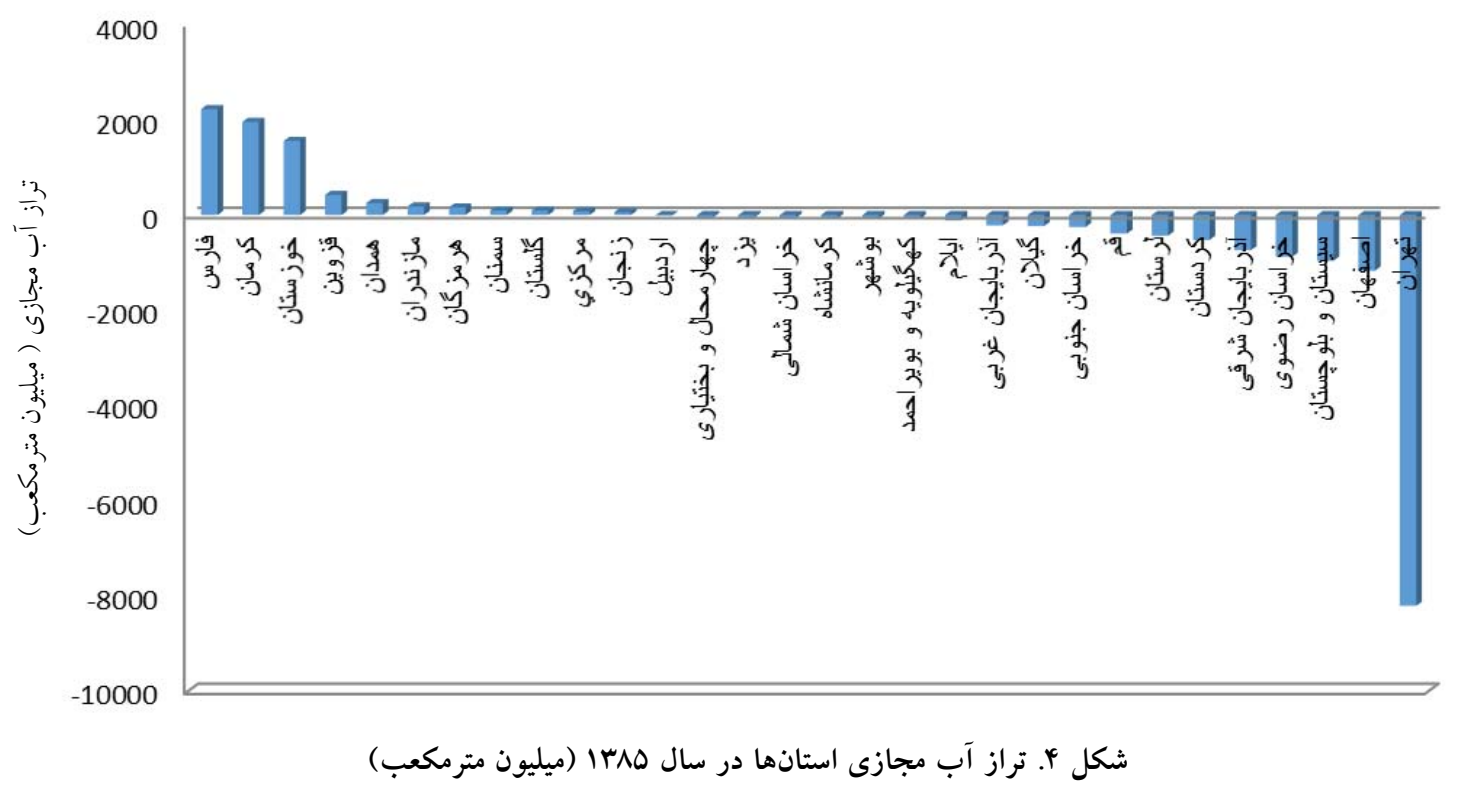




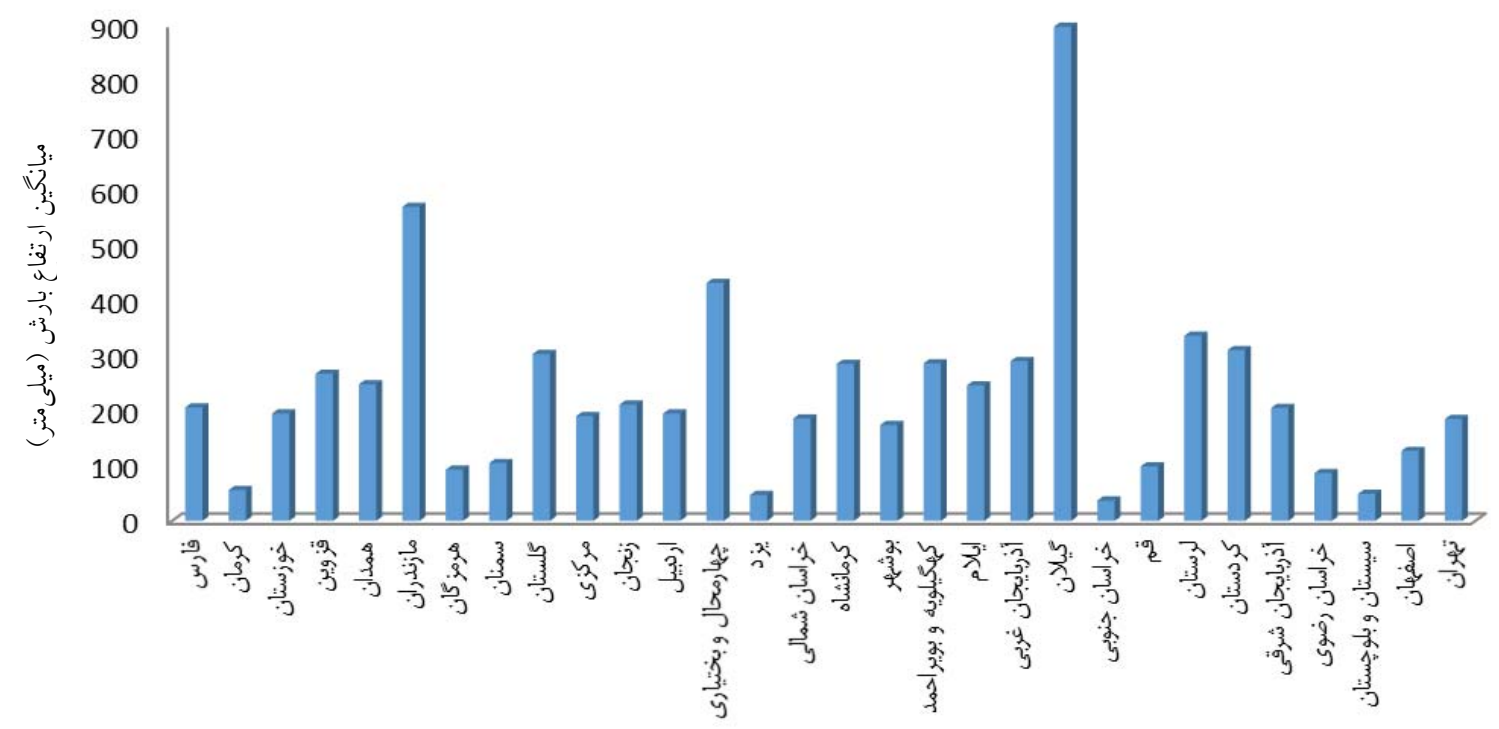

شكل ه. ميانگين ارتفاع بارش استانها در سال هیrا (ميلىمتر )

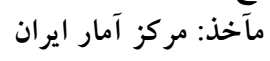

كشاورزى (و بالتبع آب مصرف شده جهت توليد آنها)، اصـلاح رزيم غذايى و الكوى مصرف مطابق با فراوانى منـابع آب (مـثلاً

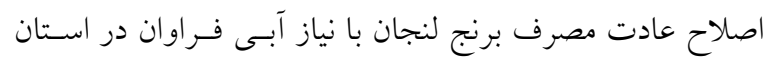
كم باران اصفهان) مىتواند سودمند واقع كردد.

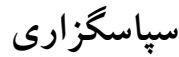

اين يزوهش با اسـتفاده از اعتبـارات ئزوهشى دانشـحاه شهـيد

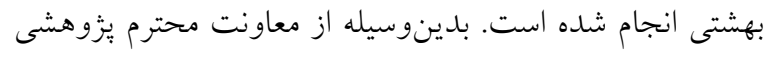
دانشگاه تقدير و تشكر مى گردد.
كالاهايى باشند كه از آب در توليد آنها كمتر استفاده شده باشـــ

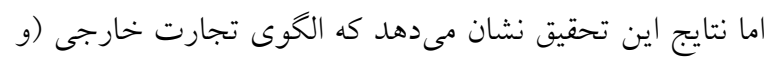

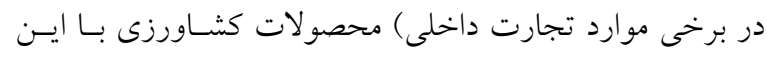

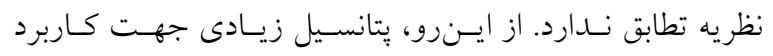

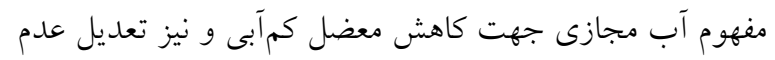

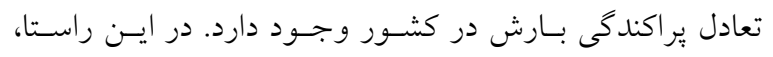

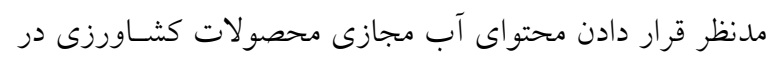

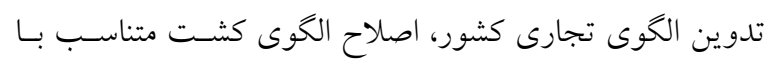

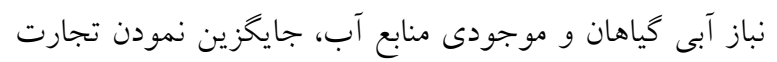

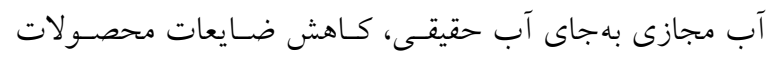

منابع مورد استفاده

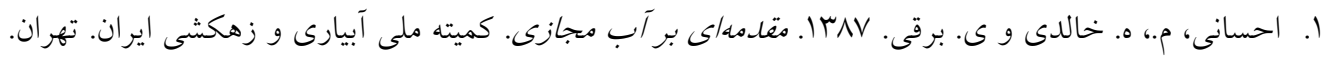

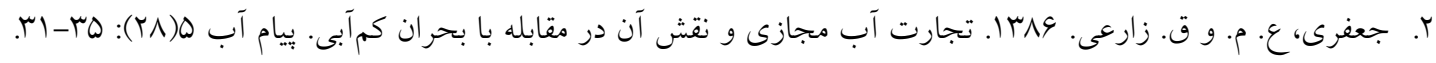

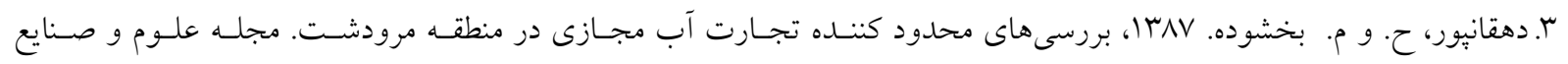

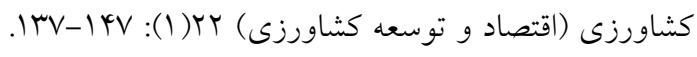

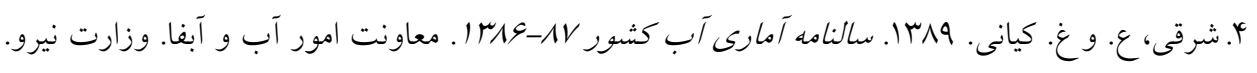




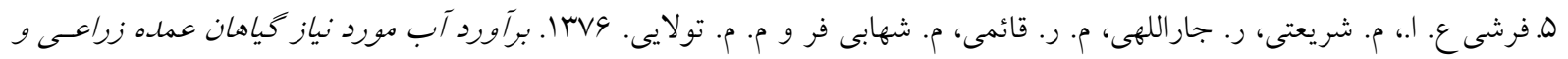

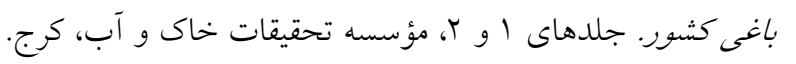

6. Allan, J. A. 1998. Virtual water: A strategic resource global solution to regional deficits. Groundwater 6(4): 545546.

7. Chapagain, A. K. and A. Y. Hoekstra. 2003. Virtual water flows between nations in relation to trade in livestock and livestock products. UNESCO-IHE, Value of Water Research Report Series No. 13.

8. Chapagain, A. K. and A. Y. Hoekstra. 2004. Water footprints of nations. UNESCO-IHE, Value of Water Research Report Series No. 16, Vol. 1 and 2.

9. Chapagain, A. K. and S. Orr. 2009. An improved water footprint methodology linking global consumption to local water resources: A case of Spanish tomatoes. J. Environ. Manage. 90: 1219-1228.

10. Guan, D. and K. Hubacek. 2007. Assessment of regional trade and virtual water flows in China. Ecol. Econ. 61: 159-170.

11. Fao.2008. www.faosta.fao.org.

12. Fracasso, A. 2014. A gravity model of virtual water trade. Ecol. Econ. 108: 215-228.

13. Hoekstra, A. Y. and A. K. Chapagain. 2007a. Water footprints of nations: Water use by people as a function of their consumption pattern. Water Resour. Manage. 21: 35-48.

14. Hoekstra, A. Y. and A. K. Chapagain. 2007b. The water footprints of Morocco and the Netherlands: Global water use as a result of domestic consumption of agricultural commodities. Ecol. Econ. 6: 143-151.

15. Hoekstra, A. Y. and P. Q. Hung. 2002. A quantification of virtual water flows between nations in relation to international crop trade. UNESCO-IHE, Value of Water Research Report Series No. 11.

16. Islam, S. M., T. Oki, S. Kanae, N. Hanasaki, Y. Agata and K. Yoshimura. 2007. A grid-based assessment of global water scarcity including virtual water trading. Water Resour. Manage. 21: 19-33.

17. Kumar, M. D. and O. P. Singh. 2005. Virtual water in global food and water policy making: Is there a need for rethinking? Water Resour. Manage. 19: 759-789.

18. Liu, J. and H. H. G. Savenije. 2008. Food consumption patterns and their effect on water requirement in China. UNESCO-IHE, Value of Water Research Report Series No. 30.

19. Ma, J., A. Y. Hoekstra, H. Wang, A. K. Chapagain and D. Wang. 2006. Virtual versus real water transfers within China. PHILOS. T. R. SOC B:19, 361: 835-842.

20. Novo, P., A. Garrido and C. Varela-Ortega. 2009. Are virtual water flows in Spanish grain trade consistent with relative water scarcity? Ecol. Econ. 68: 1454-1464.

21. Oel, P. R. Van, M. M. Mekonnen and A. Y. Hoekstra. 2008. The external water footprint of the netherlands: quantification and impact assesment. UNESCO-IHE, Value of Water Research Report Series No. 33.

22. Velázquez, E. 2007. Water trade in Andalusia. Virtual water: An alternative way to manage water use. Ecol. Econ. 63: 201-208.

23. Verma, S., D. A. Kampman, P. Van der Zaag and A. Y. Hoekstra. 2009. Going against the flow: A critical analysis of inter-state virtual water trade in the context of India's National River Linking Program. Phy. Chem. Earth 34: 261-269.

24. Zhao J., W. Liu and H. Deng. 2005. The potential role of virtual water in solving water scarcity and food security problems in China. Int. J. Sus. Dev. World Ecol. 12: 419-428. 


\title{
Study of Domestic and International Virtual Water Trade in Iran
}

\author{
G. H. Kiani ${ }^{1^{*}}$ \\ (Received: Oct. 18-2015; Accepted: April 22-2017)
}

\begin{abstract}
Recently, virtual water trade has been introduced as a tool to solve the water scarcity of dry regions. The concept holds that water-rich countries and regions should produce and export water-intensive commodities to water-scarce countries and regions. In this study, the status of domestic and international virtual water trade was studied to assess water management in Iran in 2006 (which was considered as a normal year). The calculations showed that $18666 \mathrm{Mm} 3$ of virtual water was traded through the exchange of agricultural products between the provinces. Fars and Tehran provinces were the largest exporter and importer of virtual water, respectively. Iran imported $9626 \mathrm{Mm} 3$ and exported $2226 \mathrm{Mm} 3$ of virtual water. Water footprint was $752 \mathrm{m3} / \mathrm{cap} / \mathrm{yr}$ and water self-sufficiency was $82 \%$ in Iran. The virtual water content of the exported and imported products was $1159 \mathrm{~L} / \mathrm{kg}$ and $677 \mathrm{~L} / \mathrm{kg}$, respectively. The results showed that water-scarce provinces such as Kerman, Hormozgan and Semnan were exporters of virtual water to other provinces and abroad, whereas water-rich provinces such as Guilan, Chaharmahal and Bakhtiari, Lorestan, Kordestan, West Azarbayjan, Kohgiloyeh and Boyr-Ahmad, and Kermanshah were the importers of virtual water. Therefore, water management can be improved by the improvement in international and inter-province virtual water trade. For this purpose, the cropping pattern and consumption pattern should be adapted to the virtual-water content of agricultural products for the long-term water conditions in Iran.
\end{abstract}

Keywords: Virtual water, Water footprint, Water self-sufficiency.

1. Dept. of Economics, Faculty of Administrative Sci. and Economics, Univ. of Isfahan, Isfahan. Iran.

*: Corresponding Author, Email: gh.kiani@ase.ui.ac.ir 